\title{
The Influence of Ambient Scent Temperature on Food Consumption Behavior
}

\author{
Sarah Lefebvre \\ slefebvre@murraystate.edu \\ Dipayan Biswas \\ University of South Florida, dbiswas@usf.edu
}

Follow this and additional works at: https://digitalcommons.murraystate.edu/faculty

\section{Recommended Citation}

Lefebvre, S., \& Biswas, D. (2019). The influence of ambient scent temperature on food consumption behavior. Journal of Experimental Psychology: Applied, 25(4), 753-764. https://doi.org/10.1037/ xap0000226

This Journal Article is brought to you for free and open access by the Faculty Works at Murray State's Digital Commons. It has been accepted for inclusion in Faculty \& Staff Research and Creative Activity by an authorized administrator of Murray State's Digital Commons. For more information, please contact msu.digitalcommons@murraystate.edu. 
RUNNING HEAD: A Temperature Dimension of Scent and Consumption

\begin{abstract}
This research examines the impact of ambient odor on food consumption. The results of a field experiment and five lab experiments show that the presence of a warm ambient odor (e.g., cedarwood) versus a cool ambient odor (e.g., eucalyptus) reduces the amount of calories consumed and also leads to increased choice of lower-calorie food options. This is due to established implicit associations formed from the human body's innate physiological response to changes in ambient temperature. Specifically, exposure to a warm (vs. cool) ambient odor, influences perceived ambient temperature, which in turn alters food consumption behaviors. The results of this research extend the limited research examining the temperature dimension of odor and enhance the understanding of the role of sensory cues in influencing food consumption. Further, given calorie consumption's link to widespread obesity worldwide, this research provides important implications for health and wellbeing.
\end{abstract}

Public Significance Statement: Can a temperature dimension of odor influence eating behaviors? This research examines how a temperature dimension (cool vs. warm) of ambient odor influences food consumption, where exposure to a warm ambient odor reduces food consumption amount and increases preference for lower-calorie options.

Keywords: Olfactory cues, warm and cool scents, calorie consumption. 
Can the perceived temperature dimension of ambient odor (i.e., warm vs. cool odors) influence the total amount of calories consumed? In other words, can warm versus cool ambient odors (Krishna, Elder, \& Caldara, 2010; Madzharov, Block, \& Morrin, 2015) impact how much food a person eats or the food choices they make? Through six studies, this research examines how warm (e.g., cedarwood) versus cool (e.g., eucalyptus) ambient odors influence the amount of calories consumed and choices between high- versus low-calorie food options. Further, the underlying process of formed implicit associations between ambient odor-related temperature and food intake resulting from innate physiological responses to ambient temperature is examined. With the growing recognition of the role of the environment in influencing the overall consumption experience and the worldwide concerns related to food consumption and health (Livingston \& Zylke, 2012; McFerran \& Mukhopadhyay, 2013), this research has important conceptual and practical implications.

Prior research has focused on topics related to unhealthy consumption and has identified several subtle factors that can enhance healthy consumption. Research in this domain has examined a wide range of factors such as level of affect/cognition (Shiv \& Fedorikhin, 1999), impulsivity (Veling et al., 2017), body types of others (McFerran, Dahl, Fitzsimons, \& Morales, 2010), plate and portion size (Wansink \& van Ittersum, 2013; Reimann, Bechara, \& MacInnis, 2015), temptation (Dhar \& Wertenbroch, 2000), labeling (Trudel, Murray, Kim, \& Chen, 2015), ambient light (Biswas, Szocs, Chacko, \& Wansink, 2017), display patterns (Romero \& Biswas, 2016), and health claims (Chandon \& Wansink, 2007). We extend this literature stream and examine how certain types of ambient odors, associated with different temperature perceptions, might influence calorie consumption amounts and even food choices. 
We focus on ambient odor as a sensory cue since such cues have the ability to influence behavior in subliminal and sub-conscious/unconscious manners (Krishna, 2012) and hence are less restrictive in nature. Moreover, ambient odor is ubiquitous in all types of settings including homes and retail environments. Also, examining the cross-modal influences of an olfactionbased sensory cue like ambient odor on a haptic aspect (i.e., temperature perception) and gustatory related behavior (i.e., food consumption) provides interesting conceptual insights in the domain of sensory perceptions and cross-modal sensory influences.

Building on findings from research on the effects of ambient temperature and the underexplored area of ambient odor temperature, we hypothesize that ambient odors that induce perceptions of warmer (vs. cooler) temperatures will lead to decreased calorie consumption and reduced choice likelihood of calorific foods. We propose that this effect occurs because of implicit associations that have evolved between ambient temperature and food intake in response to innate physiological reactions to ambient temperature. We test our hypotheses with the help of a field experiment and a series of lab studies. First, study 1a, conducted as a field experiment at an optometrist's office/retail store, examined the main effect of ambient odor temperature on mindless calorie consumption. Study $1 \mathrm{~b}$ replicated this in a lab setting. Then study 2 provides evidence for the underlying process and extends the findings to a low versus high calorie food choice. Next, study 3 demonstrates additional process evidence by examining the moderating effects of temperature priming. Study 4 provides further evidence for our theorizing by exploring the moderating effects of focusing on the ambient odor. Finally, study 5 demonstrates how the effects observed in our other studies with food products are attenuated (and even directionally opposite) in the case of beverages. 


\section{Conceptual Background}

\section{Ambient Odor}

Environmental cues play a critical role in influencing human behavior. With marketing activities increasingly focusing on optimizing the overall experience, sensory atmospheric cues have become even more critical. Prior research studies on ambient odor effects have examined outcome variables such as the amount of time spent in a store (Spangenberg, Crowley, \& Henderson, 1996) and store and brand evaluations (Lwin \& Morrin, 2012; Morrin \& Ratneshwar, 2003). More specifically, consumers perceived spending less time in a store when it was scented than when it was unscented (Spangenberg, Crowley, \& Henderson, 1996), olfactory cues were found to produce more positive affect towards brands and better recall of brands in movie theater advertisements (Lwin \& Morrin, 2012), and ambient odors improved recall and recognition of both familiar and unfamiliar brands even when the odor was incongruent to the product category (Morrin \& Ratneshwar, 2015). The limited research that has investigated the relationship between environmental odors and food consumption has suggested unpleasant environmental odors suppress consumption (Wansink, 2004). Though odor has a number of dimensions, we focus on the temperature dimension of odor. While there is existing research on ambient odor in general, the temperature dimension of odor has been underexplored, with the two notable exceptions being Krishna et al. (2010) and Madzharov et al. (2015). In a seminal study, Krishna et al. (2010) found that therapeutic gel-packs infused with "pumpkin cinnamon" (i.e., warm scent) (vs. "sea-island cotton", cool scent) scent were perceived as warmer (colder). Further, participants evaluated the gel-packs more positively when the haptic property was congruent with the odor (i.e., a frozen gel pack with a cold smell (vs. warm smell) and a heated gel-pack with a warm smell (vs. cool smell)). This study demonstrated the cross-modal influences of 
olfactory cues (i.e., scents) on haptics (i.e., perceived temperature). More recently, Madzharov et al. (2015) found that warm (e.g., cinnamon) versus cool (e.g., peppermint) scent influenced spatial perceptions in retail settings and enhanced purchases of premium products.

We build on these two studies to develop our conceptual framework. However, our research differs from these prior studies in that we examine the effects of warm versus cool ambient odor on food consumption; to the best of our knowledge, this is the first research to link a temperature dimension of odor with effects on food consumption. In essence, we examine the sensory cross-modal influences of olfactory cues on haptic perceptions, which in turn influence gustatory outcomes.

\section{Ambient Temperature and Food Consumption}

Ambient temperature influences individual behaviors in various ways. For instance, warm ambient temperatures enhance decision makers' perceived closeness to others, which in turn enhances conformity (Huang, Zhang, Hui, \& Wyer, 2014). As another example, cold ambient temperature increases the need for psychological warmth, leading to an increased liking for romantic movies (Hong \& Sun, 2012).

In the context of food consumption, ambient temperature influences appetite since the human physiological system attempts to maintain an optimal core body temperature (at $\sim 98^{\circ} \mathrm{F}$ ), which is usually higher than the ambient temperature (Moellering \& Smith, 2012; Warwick \& Busby, 1990; Westerterp-Plantenga, van Marken Lichtenbelt, Cilissen, \& Top, 2002).

Interestingly, according to some researchers, $80 \%$ of food consumption can be attributed to thermoregulation of the body (Parker \& Tavassoli, 2000). To maintain this optimal core body temperature, humans prefer to stay in the thermal-neutral zone, where the body feels comfortable and in thermal homeostasis (Moellering \& Smith, 2012; van Marken Lichtenbelt, Schrauwen, 
van de Kerckhove, \& Westerterp-Plantenga, 2002). Our core body temperature is controlled by the body's thermoregulatory system, which adapts to external changes in temperature through different mechanisms, including blood flow, sweating, and shivering (Mekjavic \& Eiken, 2006).

Research in the physiological sciences shows that as ambient temperature decreases, energy intake needs to increase to maintain optimal internal body thermal levels (Kupfermann, 1991; Moellering \& Smith, 2012). In other words, when ambient temperature becomes colder, the body evokes thermal regulation by increasing activities that will generate heat (e.g., shivering; Kupfermann, 1991). Overall, there is greater energy expenditure and an increase in appetite to counteract the loss of stored calories (Moellering \& Smith, 2012; Warwick \& Busby, 1990; Westerterp-Plantenga, van Marken Lichtenbelt, Cilissen, \& Top, 2002). Further, additional energy intake (e.g., through consumption of fatty, high-calorie foods) helps in raising the internal core body thermal level and keeping it at the optimal level that the body is used to (Levine, Kotz, \& Gosnell, 2003; Moellering \& Smith, 2012; Trant \& Pangborn, 1983). This is because increased food consumption generates energy, which produces heat during the digestive process, which in turn raises the internal body temperature (Levine et al., 2003; Trant \& Pangborn, 1983). As a corollary, an increase in ambient temperature leads to loss of appetite due to reduced desire for activity and energy/calorie intake that would generate additional heat (Herman, 1993; Murray, 1987). Accordingly, prior research has shown that people tend to eat more when the ambient temperature is cold than when it is hot (Wansink, 2004). Similarly, Parker and Tavassoli (2000) found a relationship between climate and caloric intake, whereby those in hotter climates eat less, particularly when the food requires extensive energy for digestion, which would generate more heat. 
Building on these findings, our research question focuses on whether individuals' food consumption behaviors can be similarly influenced through an alternative sensory cue. Next, we further develop our proposition that the temperature dimension of odor forms implicit associations with ambient temperature, resulting in the ability of ambient odor to mimic the effects of actual ambient temperature.

\section{Warm and Cool Odor Associations}

Given the subjective and abstract nature of odors, it has been relatively difficult to classify odors under overarching dimensions unlike other sensory cues, such as colors, which have distinct dimensions, such as hue, chroma, and value (Gorn, Chattopadhyay, Yi, \& Dahl,1997). Classifications of odors have resulted in dimensions along the pleasantness of the odor, along gender lines such as "feminine" versus "masculine" odors, and along temperature lines such as cool versus warm odors (Bosman, 2006; Castello, 2014; Krishna et al., 2010).

While odor is an olfactory-related stimulus (Herz, 2000; Krishna, 2012) and temperature is related to haptics (Lederman \& Klatzky, 1987), studies have demonstrated the cross-modal influences of olfactory sensations on haptic perceptions (Krishna et al., 2010). For instance, certain odors such as cinnamon and sandalwood are perceived as warm while odors like peppermint and eucalyptus are perceived as cool (Krishna et al., 2010; Madzharov et al., 2015; Zarzo, 2013).

Why are certain odors perceived as being warm and some perceived as cool? The psychological dimensions of odor perceptions related to temperature are related to odor perceptions formed through experience and evolution (Zarzo, 2013). Research has shown that mental associations are formed with odors; for example, cedarwood is associated with wood, chopping logs and building work (Stafford, Salehi, \& Waller, 2009). Further, mental associations 
are formed with odors related to characteristics of the odor, often based on the properties of the smell (Krishna et al., 2010; Lwin, Morrin, Chong, \& Goh, 2015) and these associations can influence behavior. For example, citrus smells are typically associated with cleaning products (Lwin et al., 2015) and when a citrus odor is present, people are more likely to clean their eating areas after a snack (Holland, Hendriks, \& Aarts, 2005). In addition, through ancient times and even through references in holy scriptures, odors have been associated with the original four elements (i.e., fire, water, earth, and air) proposed by Greek scholars like Hippocrates (Tisserand, 1988). Odors associated with fire, such as sandalwood, cedarwood, and cinnamon, came to be associated as warm odors and subsequently used during winter, while odors associated with watery properties (and often grown during cold weather), such as eucalyptus, and peppermint, became associated as being cool odors and subsequently used for their cooling properties (Zarzo, 2013).

In the current research, we examine if keeping actual ambient temperature constant, whether warm versus cool ambient odor might influence calorie consumption and food choices. We predict that a warm (vs. cool) ambient odor will lead to a reduced amount of calorie consumption. We propose that this would be due to the temperature dimension of odor eliciting a learned cognitive association whereby perception of ambient temperature is altered. As a result, mimicking the physiological response to changes in temperature, a warm odor leads to perceptions of the ambience being warmer and a decrease in appetite while a cool odor leads to an increase in appetite and hence enhanced food consumption. Formally stated, we hypothesize:

Hypothesis 1 (H1): A warm (vs. cool) ambient odor will lead to: (a) decreased amount of food and total calorie consumption and (b) reduced likelihood of choosing foods with higher calorie content. 
Hypothesis 2 (H2): A warm (vs. cool) ambient odor will lead to a decreased amount of food consumption and reduced likelihood of choosing high calorie foods and this effect would be mediated by perceived ambient temperature.

\section{Study 1A: Field Experiment Examining Effects of Warm Versus Cool Ambient Odors}

\section{Method}

Odor selection pretest. We first conducted a pretest to determine the appropriate warm and cool ambient odors. Thirty-nine university students (residing in the greater metropolitan area where the field study was conducted) participated in the pretest in exchange for course credit. Participants were provided with a series of fragrance strips (eucalyptus, lavender, jasmine, cedarwood, sandalwood, and yang), one at a time. One drop of essential oil of the selected odors was dropped onto a fragrance strip and sealed in a plastic bag. The sealed fragrance strips were left overnight to absorb the scents. During the pretest, participants were asked to remove each strip from the bag, sniff the odor, and then evaluate each of the fragrance strips as to how the smell felt in terms of perceived temperature, $(1=$ very cool; 7 = very warm $)$. Between each odor evaluation, participants were directed to smell provided coffee grounds in order to perceptually clear the nasal passages (Biswas, Labrecque, Lehmann, \& Markos, 2014a). The sequence of odor presentation was counterbalanced across participants.

The results of the pretest showed that participants perceived eucalyptus $(M=2.80)$ and lavender $(M=3.41)$ to be significantly cooler than cedarwood $(M=4.31)$ and sandalwood $(M=$ 4.23; for all comparisons between the cool and warm odors, $p<.01)$. The odors used were selected based on the results of the pretest. 
Main experiment. H1a was tested in study 1a, which was a between-subjects design field experiment with two manipulated conditions (ambient odor: warm vs. cool). The study was conducted at a retail store (in collaboration with the store management) affiliated with an optometrist's office, located in a major metropolitan area in the US. The office saw patients for eye exams and the retail store sold both prescription glasses and sunglasses for women, men, and children.

Procedure. To manipulate the experimental conditions, two commercial grade odor nebulizers were placed at the opposite ends of the retail store, which also functioned as the waiting area for patients. The odor nebulizer contained 5-6 drops of essential oils (of cedarwood vs. lavender scents); the odor was 'refreshed' every 3-4 hours to maintain a consistent level of intensity for the ambient odor. The nebulizers were placed out of sight of customers to avoid any suspicion. The study was run over 4 days, with 2 days having the warm ambient odor (cedarwood) and 2 days having the cool ambient odor (lavender); the days of the week were the same for both odor conditions (Thursday and Friday) and the two days (Thursday/Friday) for each condition was randomly determined. The odor nebulizers were turned on approximately 15 minutes prior to store opening (9:00 AM) and turned off at closing (5:00 PM). The ambient temperature in the retail store was held constant at approximately $73^{\circ} \mathrm{F}$, through the use of the retail store thermostat during the entire duration of the study and store employees were instructed not to change the temperature at any time. Outside temperatures were also recorded at the start, mid-point and end of each day during the data collection period. The outside temperature and weather conditions were similar across all four days, with the outside temperature ranging from a low of $54^{\circ} \mathrm{F}$ to a high of $70^{\circ} \mathrm{F}$. 
A clear glass bowl was filled at the start of each day with 136 mini, individually wrapped unbranded chocolates and placed on the reception desk whereby customers were free to take as many of the chocolates as desired. All patients and customers picking up or ordering eyeglasses were required to approach the reception desk and sign-in with the receptionist. This signing activity allowed the receptionist to unobtrusively record the total number of customers visiting the reception area. A store employee and a research assistant recorded the average number of chocolates eaten by each customer on each of the study days. Each chocolate had 26.88 calories and hence we were able to compute the average level of calorie consumption per customer. There were 43 customers on the cool odor days and 54 customers on the warm odor days, resulting in a total of 97 customers visiting the location over the four-day study period. The dependent variable in the study was the amount of calories consumed by each customer, in a adlib eating context. The store employees had no information about the purpose of the odor or about the hypotheses.

\section{Data Analysis}

Data from the four-day collection period was analyzed using an independent samples ttest. SPSS statistical software (version 25) was used for the statistical analyses in all studies. We also report all the experimental conditions, the relevant measures collected for this project, and also details about any data exclusion.

\section{Results}

An independent samples t-test revealed a significant effect of ambient odor on calories consumed. Specifically, customers visiting the store when the ambient odor was warm (vs. cool) consumed a lower amount of calories $\left(M_{\text {warm }}=29.55\right.$ vs. $\left.M_{\text {cool }}=54.87 ; t(2)=6.86, p=.021\right)$. 
Correspondingly, when the ambient odor was warm (vs. cool), customers took fewer mini chocolates $\left(M_{\text {warm }}=1.10\right.$ vs. $\left.M_{\text {cool }}=2.04 ; t(2)=6.86, p=.021\right)$.

\section{Discussion}

The results of this field study support H1a and demonstrate that ambient odors with different temperature dimensions affect total calorie consumption and overall consumption volume. Next, study $1 \mathrm{~b}$ replicates the findings of study $1 \mathrm{a}$ in a laboratory setting.

\section{Study 1B: Replication in the Lab}

Study $1 \mathrm{~b}$ was similar to study $1 \mathrm{a}$ in terms of design and manipulation stimuli, with the key difference being that while study 1a was conducted in a field setting, study $1 \mathrm{~b}$ was conducted in a laboratory setting. This helped in improving the internal validity and also allowed us to obtain additional data, in self-reported format. In addition, study $1 \mathrm{~b}$ included a "no odor" condition as a baseline control condition. Study procedures and materials were approved by the Institutional Review Board. Study $1 \mathrm{~b}$ had three between-subjects experimental conditions (control condition vs. warm ambient odor vs. cool ambient odor).

\section{Method}

Participants. Participants for all studies were recruited from an undergraduate subject pool. Sample sizes were a function of the number of students that signed up to participate on the particular day and time the study sessions were run. Two-hundred and seventy-three undergraduate students from a major US university (47\% female; average age 22 years) participated in the study. Participants completed the study session in group sizes of up to 20, with the actual number depending on the number of participants who signed up and showed up for each session. 
Procedure. Ambient odor was manipulated in the lab through the use of a commercial grade odor nebulizer similar to the procedure in study 1a. About 5-6 drops of essential oils (of cedarwood vs. lavender odors) and approximately $355 \mathrm{~mL}$ (12-oz) of water were put in the nebulizer. The nebulizer was switched on approximately 15 minutes prior to the start of study sessions. In order to avoid contamination between the warm and cool odors, the two experimental conditions were conducted on separate random days allowing the room to clear off any residual ambient odor. The control condition was run prior to the cool and warm conditions and consisted of no odor being administered in the lab. The ambient temperature in the lab was held constant across all sessions (at $\left.\sim 72^{\circ} \mathrm{F}\right)$.

Participants first arrived at a waiting area and were then brought into the lab and seated. Every seat in the lab had a clear view of a wall-mounted television. Once seated, participants were asked to watch and evaluate a clip of a television show, which was an episode of the popular TV show "Shark Tank." This was done to induce an adlib eating context, similar to the approach used in prior research (Biswas, Szocs, Krishna, \& Lehmann, 2014b). Participants were provided with 45 grams of plain M\&Ms and told a local retailer had donated the chocolate candies for participants to enjoy in the research lab. They were told they could have as much or as little of the M\&Ms as they wanted. Overall consumption volume of the M\&Ms and total calories consumed served as the key dependent variables. This was measured by the number of grams consumed during the approximately 15-minute session. Towards the end of the survey, to examine potential alternative explanations, participants were asked to indicate their sense of smell $(1=$ very weak; 7 = very strong $)$. The study session concluded with demographic questions. 


\section{Data Analysis}

All 273 participants completed the study and were included in the final analysis. A oneway analysis of variance (ANOVA) was conducted using SPSS statistical software. Bonferroni post-hoc tests were conducted to examine the comparisons at each level of the independent variable. Lastly, to rule out potential confounding variables, an ANCOVA was conducted.

\section{Results}

Main effects. Consistent with H1a and the results observed in study 1a, a one-way ANOVA revealed a significant effect of ambient odor on consumption volume $(F(1,270=$ $\left.12.38, p<.001, \eta_{\mathrm{p}}{ }^{2}=.084\right)$. Post-hoc tests were conducted to examine the variance between each condition. Participants in the warm ambient odor condition consumed a lower amount of calories $\left(M_{\text {warm }}=73.10 ; 14.62\right.$ grams $)$ than those in the control condition $\left(M_{\text {control }}=114.45 ; 22.89\right.$ grams, $t(270)=2.56, p=.011)$ and the cool condition $\left(M_{\text {cool }}=151.35 ; 30.27\right.$ grams, $t(270)=4.97, p<$ .001). In addition, participants in the cool condition consumed significantly more than those in the control condition $(t(270)=2.50, p=.013)$.

\section{[INSERT FIGURE 1 ABOUT HERE]}

Ruling out alternative explanations. To assess the impact of participants' ability to smell the ambient odor, an ANCOVA was conducted to examine the effect of ambient odor temperature on consumption volume with self-reported sense of smell as a covariate. The effect of self-reported smell ability was not significant $(p=.84)$.

\section{Discussion}

The results of study $1 \mathrm{~b}$ replicated the main effects of study $1 \mathrm{a}$ in a controlled lab setting with a control condition. This study provided support for our experimental assumptions and also 
ruled out sense of smell as a potential covariate. The results of this study also suggest that the effects of ambient odor on calorie consumption is driven by both the warm and cool odors since they are both significantly different from the control condition. Next, study 2 provides evidence for the underlying process through a test of mediation.

\section{Study 2: Process Evidence Through Mediation Test}

We theorized that the ambient odor would influence perceived temperature, which in turn would influence food choices (H2). This hypothesis was tested in study 2, which was a betweensubjects experiment with two manipulated conditions (ambient odor: warm vs. cool). Also, while studies $1 \mathrm{a}$ and $1 \mathrm{~b}$ examined H1a by focusing on total amount of calories consumed, in study 2 we examined the effects on choice involving a set of high-calorie and low-calorie options (i.e., H1b).

\section{Method}

Participants. Sixty-four undergraduate students from a major US university (58\% female; average age 21 years) participated in the study.

Procedure. The procedure was similar to that of study $1 \mathrm{~b}$, whereby participants entered a lab that had either a warm or a cool ambient odor. To enhance the robustness of the findings of study 1a and study 1b, a different set of odors was used - cinnamon (warm) and wintergreen (cool). A pretest was conducted with a separate group of undergraduate students $(n=28 ; 57 \%$ female; average age 22 years) to ensure that the odor manipulation was appropriate. Participants were sequentially provided with each odor on a strip and asked to smell coffee grounds inbetween to clear the nasal passages. For each odor, participants were asked: "in terms of perceived temperature, how does the scent make you feel?" $(1=$ cold, $7=$ warm $)$. The results of 
a paired samples t-test support the odor temperature manipulation whereby cinnamon was rated as being warmer $(M=4.21)$ than wintergreen $(M=2.14 ; t(27)=4.40, p<.001)$. Based on the pretest results, cinnamon and wintergreen were selected as the warm and cool odors, respectively.

In the main study, participants were asked to watch a 10-minute clip of a popular television show to allow for prolonged exposure to the odor. For the key dependent measure, participants were presented with a food choice scenario involving 100-calorie Oreos (low calorie) and chocolate covered Oreos (high calorie) and asked to indicate which snack they would prefer to have at that moment (Biswas et al., 2017; Wilcox, Vallen, Block, \& Fitzsimons, 2009). We measured the mediator, perceived temperature, by asking participants: "How cold/warm are you right now?" ( $1=$ cold, $7=$ warm). Participants were also asked demographic questions related to self-identified gender and age.

\section{Data Analysis}

One participant failed to complete multiple sections of the questionnaire and was removed from the analysis, leaving us with a sample of 63 participants. A binary logistic regression was conducted to assess the impact of ambient odor (warm vs. cool) on food choice. A mediation analysis was conducted using the PROCESS (version 2) macro Model 4 (Hayes 2013) with 5000 bootstrapped samples to assess the impact of ambient odor on food choice through perceived temperature.

\section{Results}

Main effects. Participants in the warm odor condition directionally chose the low-calorie snack to a greater extent than those in the cool odor condition though the effects were not 
significant at the .05 level Proportion $_{\mathrm{warm}}=80 \%$ vs. Proportion $_{\mathrm{cool}}=57 \% ; \chi^{2}=3.65, p=.056$, Cramer's $V=.24)$.

Process evidence. There was an indirect effect for the mediation model at the $90 \% \mathrm{CI}$ level (B = -.255, SE = .222, $\mathrm{CI}_{90}$ : [-.771, -.012]), implying mediation effects at the $90 \% \mathrm{CI}$ level. The direct effect was not significant $\left(\mathrm{B}=-.903, \mathrm{SE}=.593, \mathrm{CI}_{90}:[-1.882, .0758]\right)$. These results provide some evidence for perceived temperature as the mediator for the effects of ambient odor on food choice.

\section{Discussion}

Study 2 provides evidence for the underlying process by demonstrating how perceived temperature mediates the effects of warm versus cool ambient odors on choices involving foods with different calorie levels. This finding supports our theorizing related to formed association, whereby warm (cool) odor leads to perceptions of warmer (cooler) ambient temperature, which in turn influence associated food consumption responses. It is noteworthy that while studies 1a and $1 \mathrm{~b}$ with food consumption as the outcome variables had significant effects, the effects were marginal in the case of study 2, which involved food choices. Moreover, the mediation effects were also at the $90 \%$ CI level instead of at the $95 \%$ CI level. So, overall, the strength of effects for this study, is relatively weak. Next, study 3 explores the underlying process further by examining the moderating effects of priming temperature cues.

\section{Study 3: Additional Process Evidence}

Study 3 provides additional process evidence by demonstrating that the effects of ambient odor on food consumption are primarily due to ambient odor influencing perceived ambient temperature, which is associated with food consumption behaviors. In the previous studies, the 
temperature dimension of odor had an impact on perceived ambient temperature of the individual at the sub-conscious level. Research has shown that making a stimuli conscious increases it's accessibility and reduces its' downstream effects (Biswas, Keller, \& Burman, 2012; Schwarz et al., 1991). Temperature priming through an alternative form (e.g., a written dialogue) is expected to make ambient temperature a conscious dimension of the environment, and attenuate the effect of the temperature dimension of odor on perceived ambient temperature. Thus, a moderating effect of temperature priming should underscore the influence of ambient odor temperature on perceived ambient temperature. Moreover, while study 2 demonstrated process evidence through a test of mediation, study 3 provides process evidence through examining the moderating effects of the underlying process variable (e.g., Pham, Hung, \& Gorn, 2011). The results of study 2 demonstrate that the perceived ambient temperature mediates the effects of ambient odor on calorie consumption. So, if consumers are primed to think about ambient temperature, then the effects of ambient odor should be weakened since concentrating on the underlying variable should weaken the effects (Schwarz et al., 1991; Schwarz \& Clore, 1983). Thus, we hypothesize: Hypothesis 3 (H3): The effects predicted by $\mathrm{H} 1$ would hold in the absence of any priming but would be weakened when temperature thoughts are primed.

\section{Method}

Design. A 2 (ambient odor: warm vs. cool) X 2 (temperature priming: absent vs. present) between-subjects experiment was conducted.

Participants. One hundred and sixteen university students (63\% female; average age 22 years) completed the study in exchange for course credit.

Procedure. Participants completed the session in a partitioned area of a computer lab. Each participant was assigned to a computer along with a $180 \mathrm{~mL}$ (6-oz) white Styrofoam cup 
containing 40 grams of M\&Ms, equivalent to 200 calories, and an instruction sheet placed in front of the keyboard. To manipulate the ambient odor, two odor nebulizers were strategically and unobtrusively set up in the lab. Based on the results of pretest 1 (discussed earlier, in the context of study 1a), eucalyptus (cool) and cedarwood (warm) were used as the ambient odors.

To rule out possible alternative explanations related to participants' comfort, thirst, and hunger level, participants were asked (prior to completing the priming task): "How comfortable are you right now?', “How thirsty do you feel right now?” and "How hungry do you feel right now?" $(1=$ not at all, 7 = very). To manipulate temperature priming, participants in the cool (warm) ambient odor condition were asked to write about an experience where they felt cold (hot). Specifically, they were told: "In this task we would like you to recall an experience you had in a cold (hot) environment, that is, where you felt cold (hot). Please write about this experience in as much detail as possible. Where did the experience occur? What was the weather like? How did you feel?" No such task was given in the "prime absent" condition.

As in studies $1 \mathrm{~b}$ and 2 , to create an adlib food consumption task and to allow for prolonged exposure to the odor, participants reviewed a clip of a popular television show during which they were allowed to consume as much or as little of the provided snack as they would like. The key dependent variable was the overall consumption volume and the corresponding amount of calories consumed.

\section{Data Analysis}

All participants completed the study session appropriately and were included in the final analysis $(n=116)$. A 2 (ambient odor) x 2 (priming) ANOVA was conducted to assess the interaction effect. An ANCOVA was conducted to rule out the alternative explanations.

\section{Results}


There was an overall main effect of odor, whereby those in the cool odor consumed more calories than those in the warm odor $\left(M_{\mathrm{cool}}=123.17 ; 24.63\right.$ grams $)$ vs. $M_{\text {warm }}=83.2 ; 16.64$ grams); $\left.F(1,112)=5.42, p=.022, \eta_{\mathrm{p}}^{2}=.046\right)$. The main effect of priming was nonsignificant $\left(F(1,112)=2.60, p=.11, \eta_{\mathrm{p}}{ }^{2}=.02\right)$. The 2 (ambient odor) $\mathrm{X} 2$ (priming) interaction effect on calorie consumption was significant $\left(F(1,112)=4.82, p=.030, \eta_{\mathrm{p}}^{2}=.041\right)$. Moreover, consistent with $\mathrm{H} 3$, in the absence of any prime, warm (vs. cool) ambient odor led to lower calorie consumption $\left(M_{\text {warm }}=78.21 ; 15.64\right.$ grams $)$ vs. $M_{\text {cool }}=155.83 ; 31.17$ grams $) ; F(1,112)=$ $\left.10.24, p=.002, \eta_{\mathrm{p}}{ }^{2}=.084\right)$; in contrast, with temperature priming, the effects were attenuated $\left(M_{\text {warm }}=90.80 ; 18.10\right.$ grams $)$ vs. $M_{\text {cool }}=88.33 ; 17.64$ grams $) ; F(1,112)=.01, p=.92, \eta_{\mathrm{p}}^{2}=$ $.000)$.

\section{[INSERT FIGURE 2 ABOUT HERE]}

Ruling out alternative explanations. To assess the impact of participants' level of hunger, thirst, and comfort in the ambient odor temperature and consumption volume relationship, an ANCOVA was conducted with hunger, thirst, comfort as covariates. The main effect of odor remained significant $\left(F(1,109)=6.08, p=.015, \eta_{\mathrm{p}}^{2}=.055\right)$. The effect of priming also remained nonsignificant and comfortable and thirst were nonsignificant covariates in the model. Hunger was a significant covariate $\left(F(1,109)=6.64, p=.011, \eta_{\mathrm{p}}^{2}=.057\right)$. The interaction of ambient odor and priming remained significant on consumption volume $(F(1,109)$ $=3.97, p=.049, \eta_{\mathrm{p}}^{2}=.035$ ), as did the contrast analyses at each level of priming (prime absent: $p=.002, \eta_{\mathrm{p}}{ }^{2}=.085$; prime present: $\left.p=.739, \eta_{\mathrm{p}}{ }^{2}=.000\right)$. These results rule out comfort, thirst, and hunger as significant factors in explaining the observed effects of ambient odor on calorie consumption.

\section{Discussion}


The findings of study 3 provide further process evidence for our theorizing. In addition, it highlights the link between ambient odor and perceived temperature driving the effects for food consumption. Interestingly, primed to think about temperature led to a greater consumption volume for the cold ambient odor than for the warm ambient odor. This is possibly because the warm ambient odor helped in curbing indulgence and thinking about temperature did not necessarily lead to more indulgence. In contrast, for the cool ambient odor, primed to think about cold temperature helped in cutting down consumption. Next, study 4 examines how focusing on the ambient odor moderates the effect.

\section{Study 4: Moderating Effects of Focusing on Odor}

Study 4 attempted to provide further process evidence for our theorizing, by examining how focusing on the ambient odor might moderate the effects observed in our earlier studies. When decision makers focus on the factor that is instrumental in causing the effect, the effect tends to attenuate (Biswas et al., 2014b; Schwarz et al., 1991; Schwarz \& Clore, 1983). That is, focusing on the ambient odor should attenuate the effects observed in the previous studies since being aware of the causal factor tends to correct judgment biases (Biswas et al., 2014b; Schwarz et al., 1991). So, if the warm versus cool ambient odors are indeed driving the effects for calorie consumption and choice, focusing on the ambient odor should diminish the effects. Formally stated, we hypothesize:

Hypothesis 4 (H4): The effects predicted by $\mathrm{H} 1$ would hold in the absence of any explicit focus on the ambient odor and would be attenuated when participants are made to focus on the ambient odor.

\section{Method}


Design. Study 4 tested H4 with the help of a 2 (ambient odor: warm vs. cool) X 2 (focus on ambient odor: absent vs. present) along with a control condition (of no ambient odor, focus on ambient odor absent), between-subjects experiment.

Participants. One hundred and seventy-seven students (50\% female; average age 23 years) from a major US university participated in exchange for extra credit.

Procedure. To enhance the robustness of our findings, we used the other two odors supported by our pretest 1 results - sandalwood (warm) and eucalyptus (cool). Moreover, in study 4, we included a control condition of no artificial ambient odor being present.

Ambient odor was emitted in the same manner as in studies $1 \mathrm{~b}-3$ and the overall procedure was the same as well. After participants arrived at the lab, in the "focus present" condition, participants were asked a series of questions about the ambient odor, at the beginning of the survey. The questions included: "How would you rate the ambient scent in the room?" $(1=$ very bad, 7 = very good), "The ambient scent in the room seems to be:" $(1=$ very unpleasant, $7=$ very pleasant) and "How would you rate the intensity of the ambient scent in the room?" $(1=$ not at all intense, $7=$ very intense). In the "focus absent" condition, these questions were asked at the end, after participants had completed the rest of the survey, and right before participants left the lab. In the control condition, there was no ambient odor and the questions related to the ambient odor were asked at the end (similar to the "focus absent" condition).

Participants were presented with a food choice scenario involving 100-calorie Oreos (low calorie) and chocolate covered Oreos (high calorie) and asked to indicate which snack they would prefer to have at that moment (Biswas et al., 2017; Wilcox et al., 2009). The response to the food choice served as the dependent measure.

\section{Data Analysis}


All participants completed the study session and were included in the final analysis. A 2 (ambient odor: warm vs. cool) x 2 (focus on odor) binary logistic regression was conducted. To examine the effects against the hanging control condition (no odor, no focus on odor), a layered crosstabs analysis was used.

\section{Results}

A 2 (ambient odor) X 2 (focus on odor) logistic regression $(n=115)$ on food choice (low vs. high calorie snack) was conducted. The overall main effects of scent $(1=$ warm, 2 = cool; Wald $\chi^{2}=.96, p=.33$, odds ratio $\left.=.58\right)$ and focus $\left(0=\right.$ absent, $1=$ present; Wald $\chi^{2}=2.41, p=$ .12 , odds ratio $=.41$ ) were not significant. The results revealed a significant interaction effect of scent and focus (Wald $\chi^{2}=4.28, p=.039$, odds ratio $=5.15$ ). Follow-up tests showed that in the absence of a focus on the ambient odor, participants in the warm (vs. cool) ambient odor condition chose the low-calorie option to a greater extent (Proportion $_{\mathrm{warm}}=75 \% \mathrm{vs}$. Proportion $_{\mathrm{cool}}=50 \% ; \chi^{2}=3.85, p=.05$, Cramer's $\left.V=.26\right)$. When participants were made to focus on the ambient odor, the effects were attenuated Proportion $_{\text {warm }}=55 \%$ vs. Proportion $_{\text {cool }}=$ $68 \% ; \chi^{2}=.97, p=.33$, Cramer's $\left.V=.07\right)$. These results support H4.

We also compared these values with the control condition (of no ambient odor and "no focus"). In the control condition, $43.55 \%$ of the participants chose the low-calorie option, which was statistically similar to the "no focus" cool ambient odor condition $\left(\chi^{2}=.34, p=.56\right.$, Cramer's $V=.06)$ but significantly lower than the "no focus" warm ambient odor condition $\left(\chi^{2}=\right.$ 7.67, $p=.006$, Cramer's $V=.30)$.

[INSERT FIGURE 3 ABOUT HERE]

\section{Discussion}


While the results of study $1 \mathrm{~b}$ demonstrated that the effects are driven by both warm and cool odors (as they were both significantly different than the control condition), the results of study 4 suggest that the effects are primarily being driven by the warm ambient odor condition since the cool ambient odor condition led to similar outcomes as the control condition of no ambient scent. One key distinction between studies $1 \mathrm{~b}$ and 4 is that in study $1 \mathrm{~b}$, the dependent variable was consumption amount while in study 4 , the dependent variable is choice between food options. Additional research is needed to determine if this can influence the strength of effects between the cool odor and control conditions. Next, study 5 examines how the effects observed in our studies so far with solid foods might be different in the case of beverages.

\section{Study 5: Solid Foods versus Beverages}

We conceptualized that when ambient temperature is perceived to be warmer (cooler), the innate response is to decrease (increase) caloric intake due to the body's needs to maintain its internal core temperature. Studies 1a - 4, conducted with solid foods, supported this claim. However, in those studies we did not examine the effects of warm/cool ambient odors on consumption of beverages. Would the effects of warm versus cool ambient odor on consumption of foods and beverages be similar or would they be different? We propose that the effects will be in opposite directions for foods versus non-alcoholic beverages. (The effects of alcohol have known physiological effects on the body; however, examining the effects of alcoholic beverages is beyond the scope of the current research).

As discussed earlier, additional (reduced) food intake warms (cools) up the body, which in turn leads to a greater (lesser) amount of food consumption when ambient temperature is cooler (warmer). In contrast, additional beverage consumption cools the body and hence an 
increased ambient temperature is associated with a greater amount of beverage consumption (Wansink, 2004). So, the findings observed in our earlier studies, with foods, should be reversed in the case of beverages. That is, we hypothesize:

Hypothesis 5 (H5): For solid foods, warm (vs. cool) ambient odor will lead to a decreased amount of consumption. In contrast, for beverages, warm (vs. cool) ambient odor will lead to an increased amount of consumption.

\section{Method}

Design. Study 5 tested H5 with the help of a 2 (ambient odor: warm vs. cool) X 2 (consumed product: food vs. beverage) between-subjects experiment.

Participants. One hundred students from a major US university (45\% female; average age 24 years) participated in the study in exchange for course credit.

Procedure. The first factor was manipulated in a similar manner as in the previous lab studies, using a commercial grade odor nebulizer, with the ambient odors being cedarwood (warm) and eucalyptus (cool). Participants were brought in to a lab and were asked to watch and evaluate a series of international advertisements, none of which had any food elements or contents. Watching the ads created an adlib eating context (Biswas et al., 2014b). Participants were provided with either a solid food (40 grams of M\&Ms) or a beverage (175 mL of water sweetened with 60 grams of sugar per 3.79 liters ( 1 gallon). Both the food and the beverage were provided in the same $240 \mathrm{~mL}$ (8-oz) plain white Styrofoam cup; the serving cup was kept identical to avoid any potential confounds related to the cup (Krishna \& Morrin, 2008). The key dependent variable was consumption volume, measured as the percentage of the total food or beverage consumed during the 20-minute session. We use percentage of consumption as the key dependent measure instead of absolute amount of consumption since the serving weights were 
different for the food and the beverage. Measuring percentage of consumption allows us to compare the values directly between the food and beverage conditions.

\section{Data Analysis}

All participants completed the study and were included in the final analysis. A 2 (ambient odor) X 2 (food vs. beverage) ANOVA was conducted.

\section{Results}

As hypothesized, there was a significant 2 (ambient odor) X 2 (food vs. beverage) interaction effect on consumption amount $\left(F(1,96)=14.73, p<.001, \eta_{\mathrm{p}}{ }^{2}=.133\right)$. The ANOVA results revealed the main effect of ambient odor being nonsignificant $(F(1,96)=1.96, p=.17$, $\left.\eta_{\mathrm{p}}{ }^{2}=.02\right)$, while the effect of type of consumed product was significant $(F(1,96)=6.36, p=$ $.013, \eta_{\mathrm{p}}{ }^{2}=.062$ ). Consistent with the findings of our earlier studies, a warm (vs. cool) ambient odor led participants to consume less food $\left(M_{\text {warm }}=20.54 \%(8.22\right.$ grams $)$ vs. $M_{\text {cool }}=50.2 \%$ $(20.08$ grams $) ; F\left(1,96=13.33, p<.001, \eta_{\mathrm{p}}{ }^{2}=.189\right)$. In contrast, in the beverage condition, the effect of ambient odor temperature was statistically attenuated, although directionally, the warm (vs. cool) odor led to higher volume of consumption $\left(M_{\text {warm }}=28.0 \%(49.00\right.$ grams $)$ vs. $M_{\text {cool }}=$ $14.19 \%(24.83$ grams $\left.) ; F(1,96)=3.06, p=.08, \eta_{\mathrm{p}}^{2}=.008\right)$.

\section{[INSERT FIGURE 4 ABOUT HERE]}

\section{Discussion}

The results of study 5 show that the pattern of findings observed in our earlier studies, with food, is attenuated in the case of beverages. The findings of this study highlight how the state of the food, solid versus liquid, can be differentially affected by warm versus cool ambient odor. 


\section{General Discussion}

The results of six studies show that a warm (vs. cool) ambient odor leads to a reduced amount of food and calorie consumption both in field as well as in laboratory settings. We extend our results to food choices, whereby a warm (vs. cool) ambient odor led to a higher preference for options lower in calories. We also demonstrated that focusing on the ambient odor attenuates the effect. Moreover, our results suggest, the effect is influenced by perceived ambient temperature. That is, due to implicit associations formed between ambient temperature and food consumption, the temperature dimension of odor influences temperature perceptions, which in turn leads to behaviors that mimic the body's response to changes in actual ambient temperature. Finally, we demonstrated how the pattern of results observed does not extend to non-alcoholic beverages. Most of our studies involve consequential behavior, whereby participants actually consumed the foods and the calories.

The distinction between food and beverages and the different pattern of results for these are conceptually important. Prior research has often interchangeably used foods and beverages as experimental stimuli. However, as the results of our studies show, foods and beverages are processed differently and hence research studies should consider potential unintended consequences of using foods versus beverages as stimuli in experiments.

While there has been extant research examining effects of odor on individual behavior (Krishna, 2012; Krishna, Lwin, \& Morrin, 2010; Krishna, Morrin, \& Sayin, 2014; Morrin \& Ratneshwar, 2003) and limited research on the temperature aspects of odors (Krishna et al., 2010; Madzharov et al., 2015), no study has linked the effects of warm versus cool ambient odors on food consumption. Similarly, while prior research has examined effects of temperature on non-food product choices (Cheema \& Patrick, 2012) and several studies have examined the 
effects of a wide range of ambient sensory factors on food choices (Biswas et al., 2017), to the best of our knowledge, the current research is the first to demonstrate the effects of warm versus cool ambient odors on calorie consumption and choices involving high versus low calorie foods.

The findings of this research contribute to our understanding of cross-modal influences involving olfactory cues, haptic perceptions, and gustatory outcomes. Specifically, while ambient odor is an olfactory cue, perceived warmness/coolness is a haptic perception, and food consumption is gustatory related. This is possibly the first research to link olfactory cues to haptic perceptions with outcomes for gustatory factors. Hence, the findings of this research contribute to the growing literature in the domain of sensory studies (Krishna, 2012).

These findings also enhance our understanding of how the temperature dimension of ambient odor nudges healthier consumption and food choices. Given worldwide concerns related to growing obesity levels, the findings of this research have consequential implications for consumer health and wellbeing. Perceived ambient temperature plays an influential role in regulating the amount of food intake and it is interesting to note that ambient odor can induce similar reactions whereby certain "warm" odors (e.g., cedarwood) versus "cool” odors (e.g., eucalyptus) lead to similar outcomes in terms of food intake.

Our focus on calorie intake is important as consumption of high caloric foods and unhealthy foods in general are the leading contributors to the worldwide rise in obesity rates over the last three decades (Livingston \& Zylke, 2012; McFerran \& Mukhopadhyay, 2013). To elaborate, high level of obesity affects overall health and wellbeing, stigmatization, and is a significant contributor to several different illnesses, such as high blood pressure, Type 2 diabetes, and coronary heart disease (Beames, Black, \& Vartanian, 2016; CDC, 2016). From a regulatory perspective, there have been legal regulations and policies implemented to encourage healthy 
consumption. However, most of the regulatory policies have been restrictive in nature; prominent examples of such policies include the ban on sugary beverages above 16 ounces in New York City (Diehm \& Hall, 2013). Also, unfortunately, many of these restrictive regulations have proven ineffective and have frequently backfired, often due to strong reactance and resistance from individuals (Grynbaum, 2014). Our findings offer an alternative method of altering consumption behavior, in a non-restrictive manner, through environmental stimuli.

Having ambient scents in the home and in dining areas can have positive influences on overall consumer health and wellbeing, depending on calorie intake goals. Since warm (vs. cool) ambient odor leads to a lower level of food consumption, while choosing ambient odors at home, individuals who desire to consume less or make healthier choices might benefit from having warm ambient odors, such as sandalwood or cedarwood. In contrast, cool ambient odor can potentially lead to increased food intake. So, people trying to increase their calorie intake (such as someone who is underweight or is trying to gain muscle mass or general body weight) can opt for cool ambient odors during meal times.

Across all our studies, the actual temperature was kept unchanged with only the ambient odors being manipulated. Cool and warm ambient odors influenced perceived temperature, as empirically demonstrated in study 2 . This also has implications for utility and energy consumption. That is, if restaurants intend to make their customers eat more, a tempting option is to rely heavily on air-conditioning to make the ambience be perceived as colder. The findings of our studies suggest that instead of using more electricity/energy in running the air-conditioners at colder levels, a more effective, cheaper, and environmentally friendly option would be to use ambient odor. This is even more noteworthy since, according to Energy Star estimates, restaurants use two and a half times more energy per square foot than the average household. 


\section{Limitations}

We conducted a robust set of studies, both in field and lab settings, and we also used a variety of ambient odors and food items. However, our research was limited in the number of odors that could be tested and the inclusion of a control condition in only two of the studies. Moreover, though the results of warm odors were different than the control condition for both food consumption amount and choices, in the case of cool odors, the difference with the control condition was observed only in the case of food consumption amount with no difference observed in the food choice study. Clearly, future research needs to examine this discrepancy between food consumption volume and food choices.

Further, we did not test odors that are directly associated with food products (e.g., chocolate chip cookies vs. peppermint). Future research should examine how odors related to food products that are directly consumed may alter our findings. Also, there might be additional dimensions of cool versus warm ambient odors that we did not explore; future research should uncover these potential additional dimensions.

In addition, the food items used were hedonic snack items and we primarily examined scenarios involving consumption of a single product or a two-product scenario for the choice studies (studies 2 and 4). Future research should examine how the effects of cool versus warm ambient odor impact consumption when consumers get to choose from a set of multiple food options, such as in the case of a restaurant menu. We were also limited to a single non-alcoholic beverage. The results of this study may have been influenced by participants' preference for the sweetened water beverage. Future research should examine other beverages, such a popular sodas or sparkling waters to expand the findings in this area. 
Our research took place in public and in groups settings; since the presence of others may influence food consumption and choices, it would be interesting to examine how ambient odors influence these behaviors in various social settings. Lastly, although we did examine the underlying process, including through a test of mediation, there is scope for examining the underlying process and the implicit association of odors and temperature in greater depth.

In the current research, we examined effects of warm/cool ambient odors on food consumption. It might be interesting to examine how warm/cool ambient odors influence other food-related factors, such as perceived taste of the food. Also, it should be worth examining how warm/cool ambient odors affect consumption of non-food items, such as choices involving hedonic versus utilitarian options. Recognizing that food consumption is a multi-sensory process (Zampni \& Spence, 2004), it would be interesting to investigate how other sensory cues may interact with our current findings. Given the nascent state of research on effects of temperature aspects of odor, there is scope for considerable research work in this domain. 


\section{References}

Beames, J. R., Black, M. J., \& Vartanian, L. R. (2016). Predjutice toward individuals with obesity: Evidence for a pro-effect bias. Journal of Experimental Psychology: Applied, $22(2), 184-195$.

Biswas, D., Keller, L. R., \& Burman, D. (2012). Making probability judgments of future product failures: The role of mental unpacking. Journal of Consumer Psychology, 22, 237 - 248.

Biswas, D., Labrecque, L.I., Lehmann, D.R., \& Markos, E. (2014a). Making choices while smelling, tasting, and listening: The role of sensory (dis) similarity when sequentially sampling products. Journal of Marketing, 78 (1), 112-126.

Biswas, D., Szocs, C., Krishna, A., \& Lehmann, D.R. (2014b). Something to chew on: The effects of oral haptics on mastication, orosensory perception, and calorie estimation. Journal of Consumer Research, 41 (August), 261-273.

Biswas, D., Szocs, C., Chacko, R., \& Wansink B. (2017). Shining light on atmospherics: How ambient light influences food choices. Journal of Marketing Research, 54 (1), 111-123.

Bosman, A. (2006). Scents and sensibility: When do (in) congruent ambient scents influence product evaluations? Journal of Marketing, 70 (July), 32 - 43.

Castello, M. Z. (2014). Underlying dimensions in the perceptual space of perfumery odors. Flavour, 3 (Suppl 1), 20.

Centers for Disease Control and Prevention (CDC) (2016). The health effects of overweight and obesity. Retrieved from https://www.cdc.gov/healthyweight/effects/index.html

Chandon, P. J., \& Wansink, B. (2007). The biasing health halos of fast-food restaurant health claims: Lower calorie estimates and higher side-dish consumption intentions. Journal of Consumer Research, 34 (3), 301-314. 
Cheema, A., \& Patrick, V. M. (2012). Influence of warm versus cool temperatures on consumer choice. Journal of Marketing Research, 49 (6), 984 - 995.

Diehm, J., \& Hall, K. (2013, June 12). ‘Soda ban’ would target overweight, not low-income people (INFOGRAPHIC). Huffington Post. Retrieved from http://www.huffingtonpost.com/2013/06/12/soda-overweight_n_3429151.html

Dhar, R., \& Wertenbroch, K. (2000). Consumer choice between hedonic and utilitarian goods. Journal of Marketing Research, 37 (1), 60-71.

Gorn, G. J., Chattopadhyay, A., Yi, T., \& Dahl, D. W. (1997). Effects of color as an executional cue in advertising: They're in the shade. Management Science, 43 (10), 1387-1400.

Grynbaum, M.M. (2014, June 26). New York's ban on big sodas is rejected by final court. The New York Times. Retrieved from https://www.nytimes.com/2014/06/27/nyregion/cityloses-final-appeal-on-limiting-sales-of-large-sodas.html

Hayes, A. F. (2013). An Introduction to Mediation, Moderation, and Conditional Process Analysis: A Regression-Based Approach. New York: Guilford Press.

Herman, P. C. (1993). Effect of Heat on Appetite. In B.M. Marriott (Ed.), Nutritional Needs in Hot Environments (187 - 213). Washington, D.C.: National Academies Press.

Herz, R. (2000). Verbal coding in olfactory versus nonolfactory cognition. Memory \& Cognition, 28 (6), 957-964.

Holland, R. W., Hendriks, M., \& Aarts, H. (2005). Smells like clean spirit: Nonconscious effects of scent on cognition and behavior. Psychological Science, 16 (9), 689 - 693.

Hong, J., \& Sun, Y. (2012). Warm it up with love: The effect of physical coldness on liking of romance movies. Journal of Consumer Research, 39 (2), 293 - 306. 
Huang, X., Zhang, M., Hui, M.K., \& Wyer, R. S. (2014). Warmth and conformity: The effects of ambient temperature on product preferences and financial decisions. Journal of Consumer Psychology, 24 (2), 241 - 250.

Krishna, A. (2012). An integrative review of sensory marketing: Engaging the senses to affect perception, judgment and behavior. Journal of Consumer Psychology, 22 (3), 332351.

Krishna, A., \& Morrin, M. (2008). Does touch affect taste? The perceptual transfer of product container haptic cues. Journal of Consumer Research, 34 (6), 807-818.

Krishna, A., Elder, R. S., \& Caldara, C. (2010). Feminine to smell but masculine to touch? multisensory congruence and its effects on the aesthetic experience. Journal of Consumer Psychology, 20, 410 - 418.

Krishna, A., Lwin, M., \& Morrin, M. (2010). Product scent and memory. Journal of Consumer Research, 37 (June), 57-67.

Krishna, A., Morrin, M., \& Sayin, E. (2014). Smelling cookies and salivating: A focus on olfactory imagery. Journal of Consumer Research, 41 (1), 18-34.

Kupfermann, I. (1991). Hypothalamus and limbic system: Motivation. In E.R. Kandel, J.H. Schwartz, and T.M. Jessell (Eds.), Principles of Neural Science ( $3^{\text {rd }}$ edition) (750-760). Norwalk, CT: Appleton and Lange.

Lederman, S. J., \& Klatzky, R. L. (1987). Hand movements: A window into object recognition. Cognitive Psychology, 19 (3), $342-368$.

Levine, A. S., Kotz, C. M., \& Gosnell, B.A. (2003). Sugars and fats: The neurobiology of preferences. The Journal of Nutrition, 133 (3), 831S-834S. 
Livingston, E. H., \& Zylke, J.W. (2012). Progress in obesity research: Reasons for optimism. Journal of the American Medical Association, 308 (11), 1162-1164.

Lwin, M. O., \& Morrin, M. (2012). Scenting movie theatre commercials: The impact of scent and pictures on brand evaluations and ad recall. Journal of Consumer Behavior, 11 (3), $264-272$.

Lwin, M. O., Morrin, M., Chong, C. S. T., \& Goh, S. X. (2015). Odor semantics and visual cues: What we smell impacts where we look, what we remember, and what we want to buy. Journal of Behavioral Decision Making, 29 (2 - 3), 336 - 350.

Madzharov, A., Block, L., \& Morrin, M. (2015). The cool scent of power: Effects of ambient scent on consumer preferences and choice behavior. Journal of Marketing, 79 (1), 8396.

McFerran, B., \& Mukhopadhyay, A. (2013). Lay theories of obesity predict actual body mass. Psychological Science, 24 (8), 1428-1436.

McFerran, B., Dahl, D. W., Fitzsimons, G. J., \& Morales, A.C. (2010). I'll have what she's having: Effects of social influence and body type on the food choices of others. Journal of Consumer Research, 36 (6), 915 - 929.

Mekjavic, I. B., \& Eiken, O. (2006). Contribution of thermal and non-thermal factors to the regulation of body temperature in humans. Journal of Applied Physiology, 100 (6), 2065-2072.

Moellering, D. R., \& Smith, D. L. (2012). Ambient temperature and obesity. Current Obesity Reports, 1 (1), 26-34.

Morrin, M., \& Ratneshwar, S. (2003). Does it make sense to use scents to enhance brand memory? Journal of Marketing Research, 40 (1), 10-25. 
Murray, R. (1987). The effects of consuming carbohydrate-electrolyte beverages on gastric emptying and fluid absorption during the following exercise. Sports Medicine, 4 (5), 32251.

Parker, P. M., \& Tavassoli, N. T. (2000). Homeostasis and consumer behavior across cultures. International Journal of Research in Marketing, 17, 33 - 53.

Pham, M., Hung, I.W., \& Gorn, G. J. (2011). Relaxation increases monetary valuation. Journal of Marketing Research, 48 (5), 814-826.

Reimann, M., Bechara, A., \& MacInnis, D. (2015). Leveraging the happy meal effect: Substituting food with modest nonfood incentives decreases portion size choice. Journal of Experimental Psychology: Applied, 21(3), 276 - 286.

Romero, M., \& Biswas, D. (2016). Healthy left, unhealthy right: Can displaying healthy items to the left (versus right) of unhealthy items nudge healthier choices? Journal of Consumer Research, 43 (1), 103-12.

Schwarz, N., Bless, H., Strack, F., Klumpp, G., \& Rittenauer-Schatka, H. (1991). Ease of retrieval as in- formation: Another look at the availability heuristic. Journal of Personality and Social Psychology, 61 (2), 195-202.

Schwarz, N., \& Clore, G. L. (1983). Mood, misattribution and judgments of wellbeing: Informative and directive functions of affective states. Journal of Personality and Social Psychology, 45 (3), 513-523.

Shiv, B., \& Fedorikhin, A. (1999). Heart and mind in conflict: The interplay of affect and cognition in consumer decision making. Journal of Consumer Research, 26 (3), 278-292. 
Spangenberg, E. R., Crowley, A. E., \& Henderson, P. W. (1996). Improving the store environment: Do olfactory cues affect evaluations and behaviors? Journal of Marketing, 60 (2), $67-80$.

Stafford, L. D., Salehi, S., \& Waller, B. M. (2009). Odors cue memory for odor-associated words. Chemosensory Perception, 2(2), 59 - 69.

Tisserand, R. (1988). Essential oils as psychotherapeutic agents. In Van Toller and G. H. Dodd (Eds.), Perfumery: The Psychology and Biology of Fragrance (167 - 181). London, UK: Chapman \& Hall.

Trant, A.S., \& Pangborn, R.M. (1983). Discrimination, intensity, and hedonic responses to color, aroma, viscosity, and sweetness of beverage. Lebensmittel-Wissenschaft+ Technologie.

Trudel, R., Murray, K. B., Kim, S., \& Chen, S. (2015). The impact of traffic light color-coding on food health perceptions and choice. Journal of Experimental Psychology: Applied, $21(3), 255-275$.

van Marken Lichtenbelt, W. D., Schrauwen, P., van de Kerckhove, S., \& Westerterp-Plantenga, M. S. (2002). Individual variation in body temperature and energy expenditure in response to mild cold. American Journal of Physiology - Endocrinology and Metabolism, 282 (5), E1077-1083.

Veling, H., Chen, Z., Tombrock, M. C., Verpaalen, I. A., Schmitz, L. I., Dijksterhuis, A., \& Holland, R. W. (2017). Training impulsive choices for healthy and sustainable food. Journal of Experimental Psychology: Applied, 23(2), 204 - 215.

Wansink, B. (2004). Environmental factors that increase the food intake and consumption volume of unknowing consumers. Annual Review of Nutrition, 24, 455-479. 
Wansink, B., \& van Ittersum, K. (2013). Portion size me: Plate-size induced consumption norms and win-win solutions for reducing food intake and waste. Journal of Experimental Psychology: Applied, 19(4), 320 - 323.

Warwick, P.M., \& Busby, R. (1990). Influence of mild cold on 24 h energy expenditure in 'normally' clothed adults. British Journal of Nutrition, 63 (3), 481-488.

Westerterp-Plantenga, M.S., van Marken Lichtenbelt, W.D., Cilissen, C., \& Top, S. (2002). Energy metabolism in women during short exposure to the thermoneutral zone. Physiology \& Behavior, 75 (1), 227-235.

Wilcox, K., Vallen, B., Block, L., \& Fitzsimons, G. J. (2009). Vicarious goal fulfillment: When the mere presence of a healthy option leads to an Ironically indulgent decision. Journal of Consumer Research, 36 (3), 380-393.

Zarzo, M. (2013). What is a fresh scent in perfumery? Perceptual freshness is correlated with substantivity. Sensors, 13 (1), 463-483.

Zampini, M., \& Spence, C. (2004). The role of auditory cues in modulating the perceived crispness and staleness of potato chips. Journal of Sensory Studies, 19(5), 347-363. 
Figure 1: Effect of Ambient Temperature Odor on Calorie Consumption

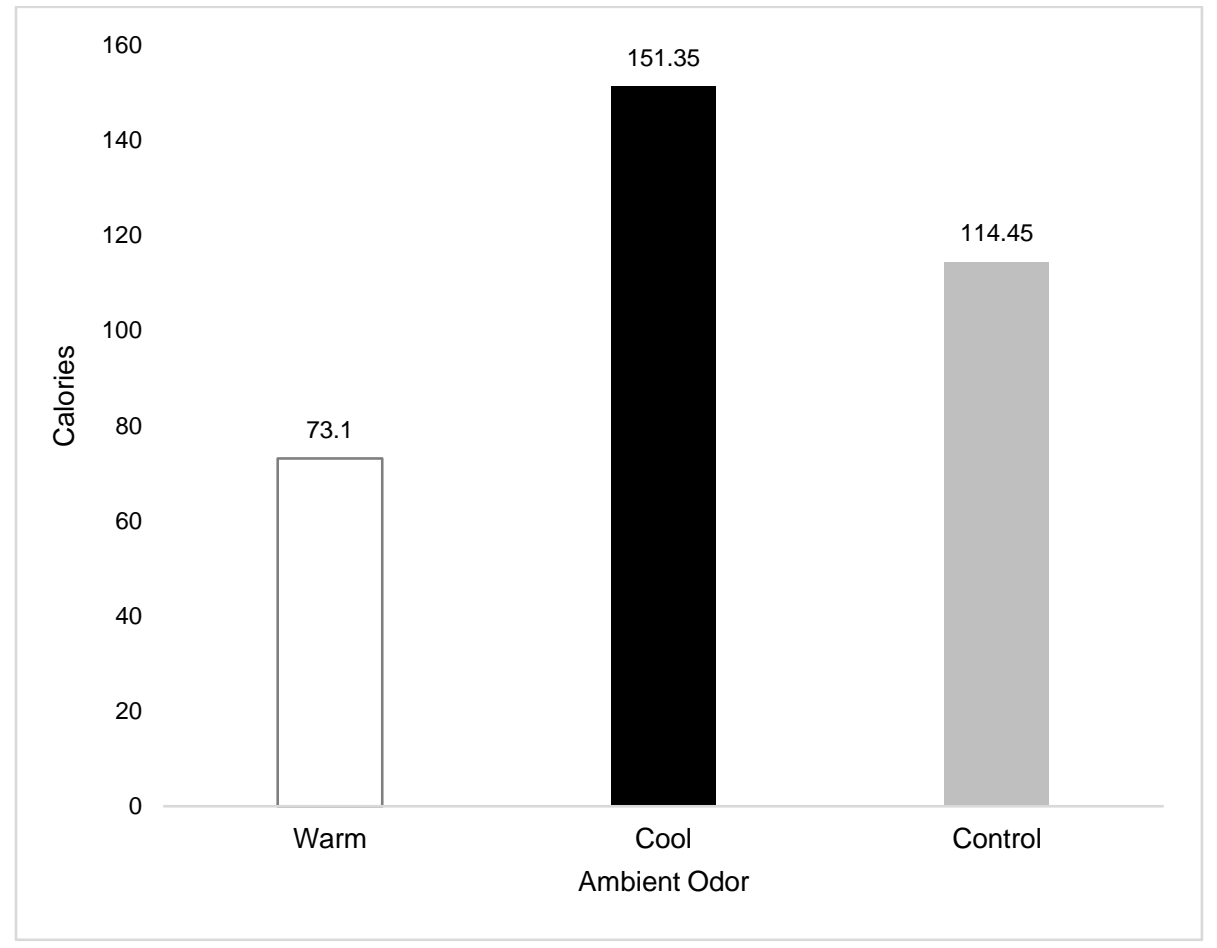

Figure 2: Interaction of Ambient Temperature Odor and Priming on Calorie Consumption

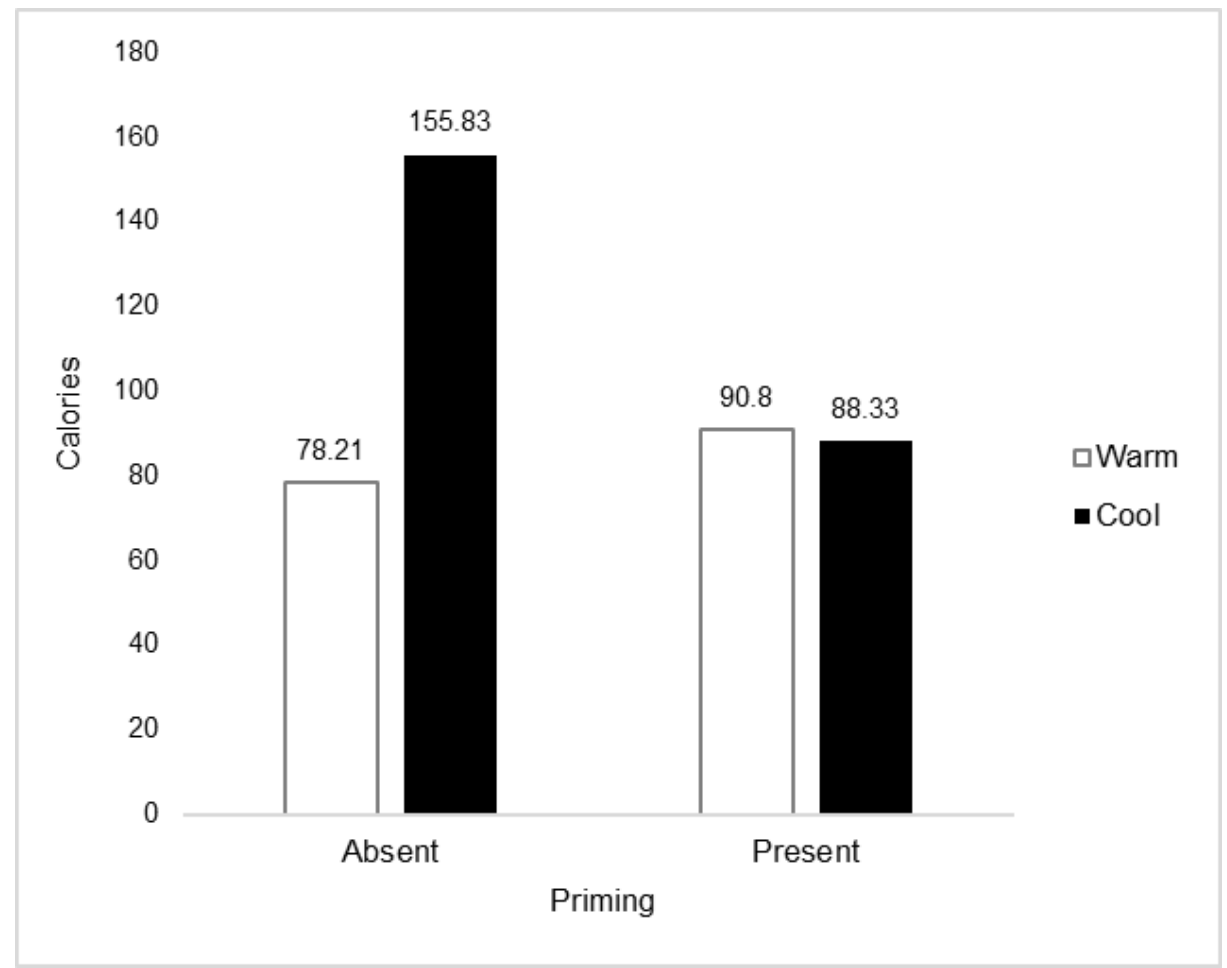


Figure 3: Impact of Ambient Temperature Odor on Choice of Low-Calorie Snack

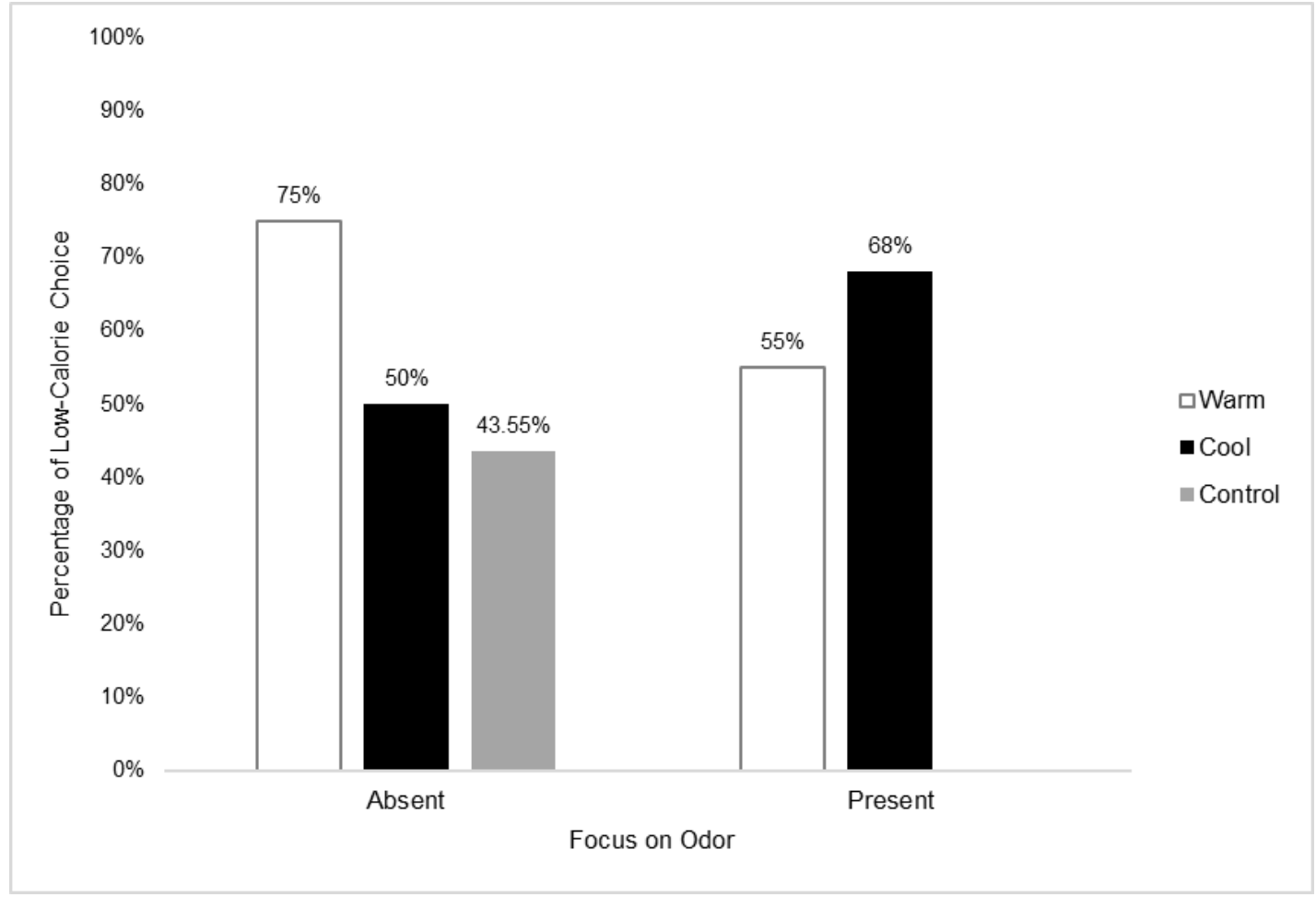

Figure 4: Effect of Ambient Temperature Odor on Food versus Beverage

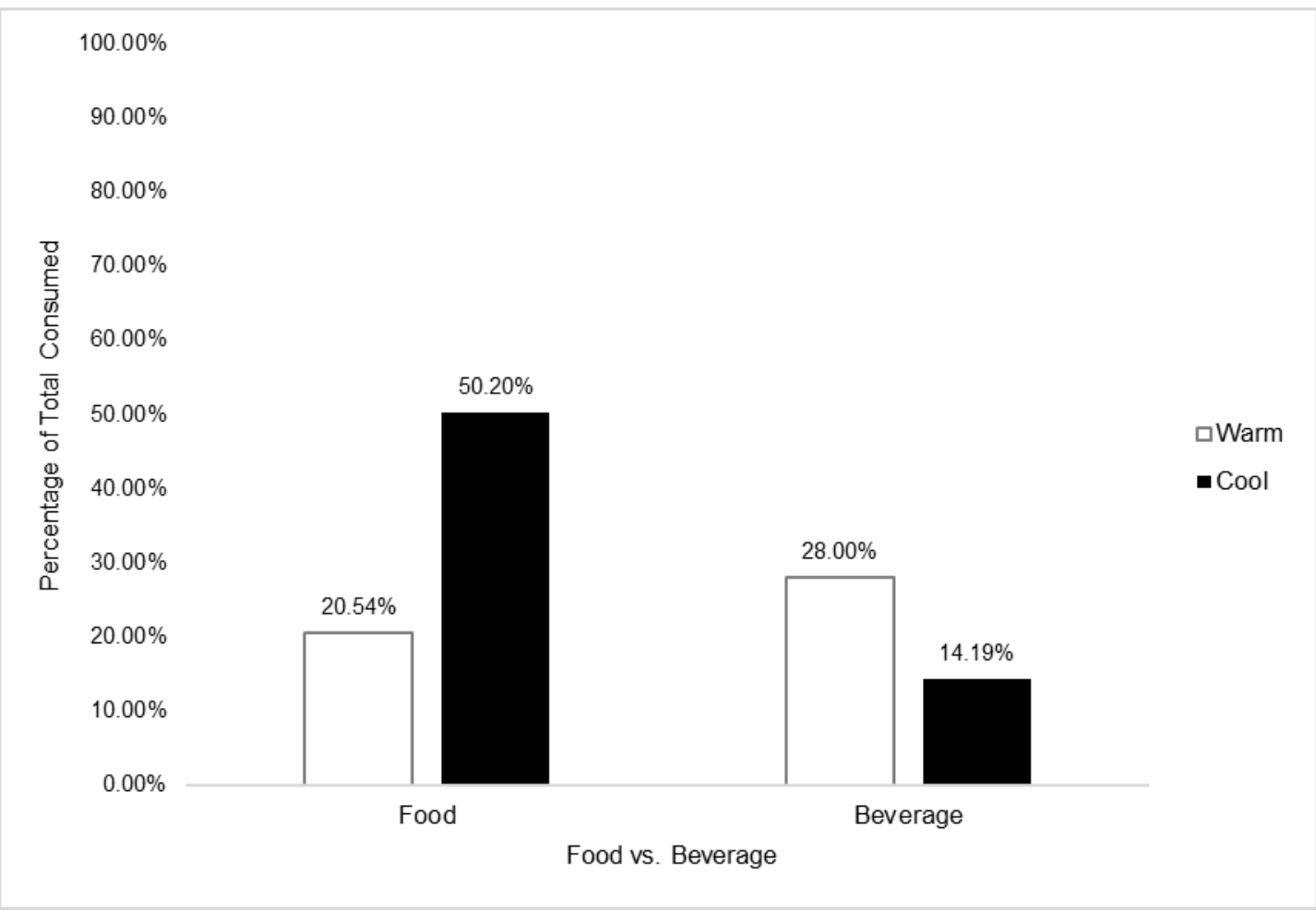

